Article

\title{
Variety and Harvesting Season Effects on Antioxidant Activity and Vitamins Content of Citrus sinensis Macfad.
}

\author{
Vanessa Cardeñosa ${ }^{1}$, João C. M. Barreira ${ }^{2}$, Lillian Barros ${ }^{2}$, Francisco J. Arenas-Arenas ${ }^{3}$, \\ José M. Moreno-Rojas ${ }^{1}$ and Isabel C. F. R. Ferreira ${ }^{2, *}$
}

1 Postharvest Technology and Agrifood Industry Area, Andalusian Institute of Agricultural and Fishering Research and Training (IFAPA) Alameda del Obispo, 14004 Córdoba, Spain;

E-Mails: vanessa.cardenosa@juntadeandalucia.es (V.C.); josem.moreno.rojas@juntadeandalucia.es (J.M.M.-R.)

2 Mountain Research Center (CIMO), ESA, Polytechnic Institute of Bragança, Apartado 1172, 5301-855 Bragança, Portugal; E-Mails: jbarreira@ipb.pt (J.C.M.B.); lillian@ipb.pt (L.B.)

3 Centro IFAPA “Las Torres-Tomejil”, Instituto de Investigación y Formación Agraria y Pesquera, Ctra Sevilla_Cazalla Km. 12,2, 41200 Alcalá del Río (Sevilla), Spain;

E-Mail: fjose.arenas@juntadeandalucia.es

* Author to whom correspondence should be addressed; E-Mail: iferreira@ipb.pt; Tel.: +351-273-303-219; Fax: +351-273-325-405.

Academic Editor: Derek J. McPhee

Received: 30 March 2015 / Accepted: 4 May 2015 / Published: 7 May 2015

\begin{abstract}
Five sweet orange (Citrus sinensis Osbeck) varieties cultivated in Huelva (Spain) and picked at two seasons during two consecutive years, were characterized for their antioxidant activity (free radicals scavenging activity, reducing power and lipid peroxidation inhibition) and vitamin content (vitamin $\mathrm{E}$ and vitamin $\mathrm{C}$ ). The effects induced by sweet orange variety and stage of maturity were comprehensively compared by applying 2-way ANOVA and linear discriminant analysis. The results indicated higher differences in antioxidant activity and vitamin contents in response to the effect of the harvesting season, when compared to the effect of sweet orange variety. Nevertheless, the results observed in 2012 showed less marked differences among the assayed sweet orange varieties. Either way, it might be concluded that oranges sampled in January show the highest antioxidant activity and vitamin contents. Furthermore, concerning the properties evaluated in this work, all sweet orange varieties represent good alternatives, except for
\end{abstract}


Rhode Summer, which would not be the preferable choice as a target to enhance sweet orange overall characteristics.

Keywords: Citrus sinensis; variety; harvesting season; antioxidant activity; ascorbic acid; $\alpha$-tocopherol

\section{Introduction}

In recent decades, researchers and consumers have become increasingly interested in a healthier diet, increasing the intake of fruit and vegetables. This is mainly justified because these foods are an important source of bioactive compounds. In fact, several authors had already suggested that a diet rich in antioxidants is directly associated with the prevention of human diseases, like several kinds of cancer, diabetes, cardiovascular diseases, neurological disorders, among others [1-3]. All these pathologies have the same underlying feature of being related with the overproduction of free radicals in the organism [1]. These chemical species are generally unstable and very reactive atoms or molecules with one or more unpaired electrons. They are usually divided in three classes: (1) reactive oxygen species; (2) reactive nitrogen species; and (3) reactive sulfur species. They are produced as a normal part of aerobic metabolism but external factors such as drugs, environmental pollutants, radiation, smoking, industrial solvents, pesticides and ozone can promote their production in the organism [4]. For normal organism functioning, it is essential to maintain the equilibrium between the production of these "reactive species" (RS) and their neutralization by antioxidant defenses, but, if the balance tends to the overproduction of RS, it is said that the organism is in oxidative stress.

Citrus fruits are an important source of antioxidant compounds to prevent oxidative stress. In particular, sweet orange fruits are considered to be rich sources of antioxidants, including vitamin $\mathrm{C}$, phenolic compounds and carotenoids [5-8]. Among these compounds, the intake of ascorbic acid (vitamin C) is critical because the human organism cannot synthesize it. Moreover, ascorbic acid is associated with a reduced incidence of various oxidative stress-related diseases such as heart disease, stroke, cancer, several neurodegenerative diseases and cataractogenesis [9,10]. On the other hand, the intake of vitamin E (tocopherols), also found in fruits and vegetables, is believed to prevent against degenerative malfunctions too, mainly cancer and cardiovascular diseases due to its role as a scavenger of free radicals [11,12].

Regarding citrus fruits production in Europe, Spain is the largest producer and exporter of sweet orange fruit. However, the strong market competitiveness demands the development of new varieties in order to improve some aspects of the crop, such as productivity and fruit quality, with clear benefits for the sweet orange growers. Previously, several citrus varieties have been found to display significantly higher levels of antioxidant activity than others, and the individual content in flavonoids and phenolic acids have been found to differ among varieties as well [13,14]. Nevertheless, studies regarding the influence of harvesting season are rather scarce. Accordingly, the main purpose of the present work was to verify possible differences in the antioxidant quality of different sweet orange varieties (Barnfield, Chislet, Lane Late, Navel Powell and Rhode Summer) grown in western Andalusia, but also evaluating if the harvesting season (January or April) may affect that quality. In 
order to validate the results, samples were harvested in two consecutive years. Finding the most suitable variety, as well as the harvesting season stage, that optimizes the antioxidant potential of this fruit might represent a valuable feature for sweet orange growers.

\section{Results and Discussion}

The $\mathrm{EC}_{50}$ values obtained for each antioxidant assay, as well as the levels of ascorbic acid and $\alpha$-tocopherol are presented in Table 1 . The assayed orange variety $(\mathrm{OV})$ showed antioxidant activity in all the performed assays, with the lowest $\mathrm{EC}_{50}$ values being obtained for $\beta$-carotene bleaching inhibition.
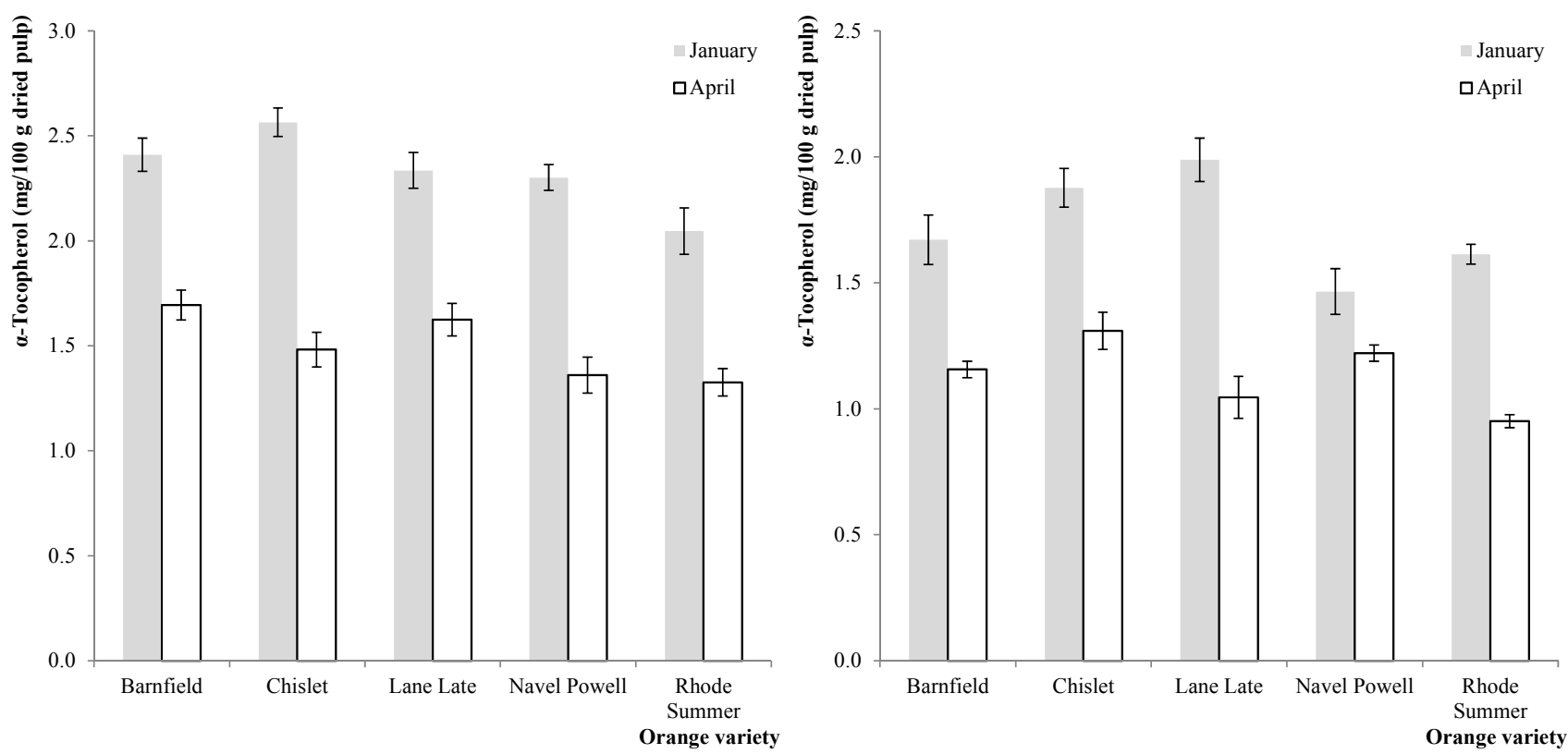

(A)

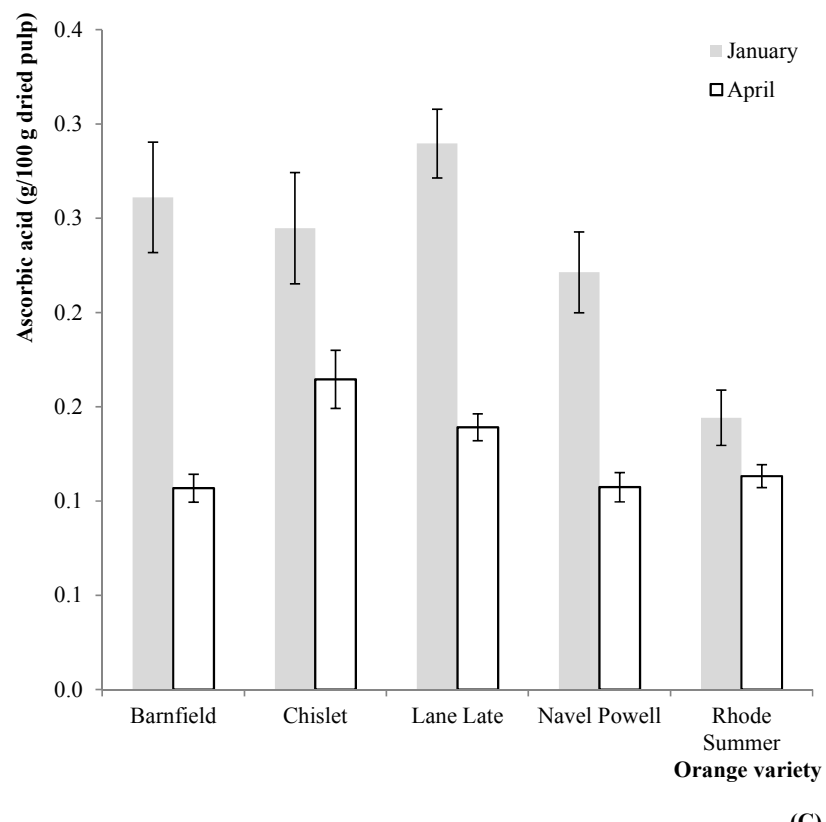

(C)

Figure 1. Estimated marginal mean plots representing the effect of harvesting season (HS) on the antioxidant vitamins of $C$. sinensis fruits. (A) $\alpha$-tocopherol (2011); (B) $\alpha$-tocopherol (2012); (C) ascorbic acid (2011). 
Table 1. Antioxidant properties ( $\mathrm{EC}_{50}$ values in $\left.\mathrm{mg} / \mathrm{mL}\right)$ and major antioxidant compounds divided by sweet orange variety $(\mathrm{OV})$ and harvesting season (HS). The results are presented as mean $\pm \mathrm{SD}$.

\begin{tabular}{|c|c|c|c|c|c|c|c|}
\hline & & \multirow{2}{*}{$\begin{array}{c}\text { DPPH Scavenging } \\
\text { Activity }\end{array}$} & \multirow[b]{2}{*}{$\begin{array}{c}\text { Reducing } \\
\text { Power }\end{array}$} & \multicolumn{2}{|c|}{ Lipid Peroxidation Inhibition } & \multirow{2}{*}{$\begin{array}{c}\alpha \text {-Tocopherol } \\
\text { (mg/100 g of } \\
\text { dry pulp) }\end{array}$} & \multirow{2}{*}{$\begin{array}{c}\text { Ascorbic Acid } \\
\text { (g/100 g of dry } \\
\text { pulp) }\end{array}$} \\
\hline & & & & $\begin{array}{c}\text { TBARS Formation } \\
\text { Inhibition }\end{array}$ & $\begin{array}{c}\beta \text {-Carotene } \\
\text { Bleaching Inhibition } \\
\end{array}$ & & \\
\hline \multicolumn{8}{|c|}{2011} \\
\hline \multirow{5}{*}{$\begin{array}{l}\text { Orange variety } \\
\qquad(\mathrm{OV})\end{array}$} & Barnfield & $9 \pm 2$ & $2.5 \pm 0.4$ & $2.0 \pm 0.5$ & $1.3 \pm 0.3$ & $2.1 \pm 0.4$ & $0.18 \pm 0.05$ \\
\hline & Chislet & $10 \pm 2$ & $3.0 \pm 0.2$ & $2.1 \pm 0.2$ & $0.4 \pm 0.1$ & $2.0 \pm 0.5$ & $0.20 \pm 0.05$ \\
\hline & Lane Late & $9 \pm 2$ & $2.5 \pm 0.3$ & $2.1 \pm 0.2$ & $0.4 \pm 0.1$ & $2.0 \pm 0.4$ & $0.21 \pm 0.05$ \\
\hline & Navel Powell & $9 \pm 2$ & $2.6 \pm 0.5$ & $2.5 \pm 0.5$ & $0.4 \pm 0.1$ & $1.8 \pm 0.5$ & $0.16 \pm 0.05$ \\
\hline & Rhode Summer & $11 \pm 1$ & $3.0 \pm 0.1$ & $4.0 \pm 0.2$ & $0.5 \pm 0.1$ & $1.7 \pm 0.4$ & $0.13 \pm 0.02$ \\
\hline$p$-value $(\mathrm{n}=18)$ & Tukey's test & $<0.001$ & $<0.001$ & $<0.001$ & $<0.001$ & 0.081 & 0.001 \\
\hline \multirow{2}{*}{$\begin{array}{l}\text { Harvesting season } \\
\text { (HS) }\end{array}$} & January & $8 \pm 1$ & $2.4 \pm 0.3$ & $3 \pm 1$ & $0.6 \pm 0.2$ & $2.3 \pm 0.2$ & $0.23 \pm 0.05$ \\
\hline & April & $11 \pm 1$ & $3.0 \pm 0.1$ & $2 \pm 1$ & $0.6 \pm 0.3$ & $1.5 \pm 0.2$ & $0.13 \pm 0.02$ \\
\hline$p$-value $(\mathrm{n}=45)$ & $t$-student's test & $<0.001$ & $<0.001$ & 0.088 & 0.696 & $<0.001$ & $<0.001$ \\
\hline$p$-value $(\mathrm{n}=90)$ & $\mathrm{OV} \times \mathrm{HS}$ & $<0.001$ & $<0.001$ & $<0.001$ & $<0.001$ & $<0.001$ & $<0.001$ \\
\hline \multicolumn{8}{|c|}{2012} \\
\hline \multirow{5}{*}{$\begin{array}{l}\text { Orange variety } \\
\text { (OV) }\end{array}$} & Barnfield & $7.8 \pm 0.1$ & $2.6 \pm 0.1$ & $4.3 \pm 0.2$ & $0.7 \pm 0.2$ & $1.4 \pm 0.3$ & $0.22 \pm 0.03$ \\
\hline & Chislet & $7.4 \pm 0.5$ & $2.5 \pm 0.2$ & $3.8 \pm 0.4$ & $0.4 \pm 0.2$ & $1.6 \pm 0.3$ & $0.21 \pm 0.02$ \\
\hline & Lane Late & $7.1 \pm 0.5$ & $2.4 \pm 0.2$ & $4 \pm 1$ & $0.7 \pm 0.1$ & $1.5 \pm 0.5$ & $0.25 \pm 0.03$ \\
\hline & Navel Powell & $8.0 \pm 0.1$ & $2.6 \pm 0.1$ & $4 \pm 1$ & $0.7 \pm 0.3$ & $1.3 \pm 0.1$ & $0.20 \pm 0.02$ \\
\hline & Rhode Summer & $7.0 \pm 0.3$ & $2.4 \pm 0.2$ & $4 \pm 1$ & $0.4 \pm 0.1$ & $1.3 \pm 0.3$ & $0.16 \pm 0.02$ \\
\hline$p$-value $(\mathrm{n}=18)$ & Tukey's test & $<0.001$ & $<0.001$ & 0.600 & $<0.001$ & 0.040 & $<0.001$ \\
\hline Harvesting season & January & $7.1 \pm 0.5$ & $2.4 \pm 0.1$ & $3.2 \pm 0.5$ & $0.5 \pm 0.2$ & $1.7 \pm 0.2$ & $0.21 \pm 0.04$ \\
\hline (HS) & April & $7.8 \pm 0.3$ & $2.6 \pm 0.1$ & $5.2 \pm 0.5$ & $0.6 \pm 0.3$ & $1.1 \pm 0.1$ & $0.20 \pm 0.03$ \\
\hline$p$-value $(\mathrm{n}=45)$ & $t$-student's test & $<0.001$ & $<0.001$ & $<0.001$ & 0.022 & $<0.001$ & 0.058 \\
\hline$p$-value $(\mathrm{n}=90)$ & $\mathrm{OV} \times \mathrm{HS}$ & $<0.001$ & $<0.001$ & $<0.001$ & $<0.001$ & $<0.001$ & 0.038 \\
\hline
\end{tabular}


The interaction effect between OV and HS was evaluated to understand if differences in antioxidant profiles or vitamin levels are specific of a determined OV or HS. The reported results are presented as the mean value of each OV for both HS, as well as the mean value of each HS, comprising values for all OV. Every time the interaction among factors (OV $\times$ HS) was significant $(p<0.05)$, acting itself as a source of variability, multiple comparison tests could not be performed. In these cases, the presented conclusions were drawn from the estimated marginal mean (EMM) plots obtained in each case. The results obtained for HS were compared using a simple $t$-test for equality of means (after checking the equality of variances through a Levene's test), since there were fewer than three groups.

As it might be depicted from Table 1, the interaction OV $\times$ HS was significant in all cases, not allowing any multiple comparison tests. Nevertheless, some particular tendencies became evident from the analysis of the correspondent EMM plots: the $\alpha$-tocopherol (in 2011, Figure 1A and 2012, Figure 1B) and ascorbic acid (in 2011, Figure 1C) levels were higher in samples collected in January for all the tested OV.

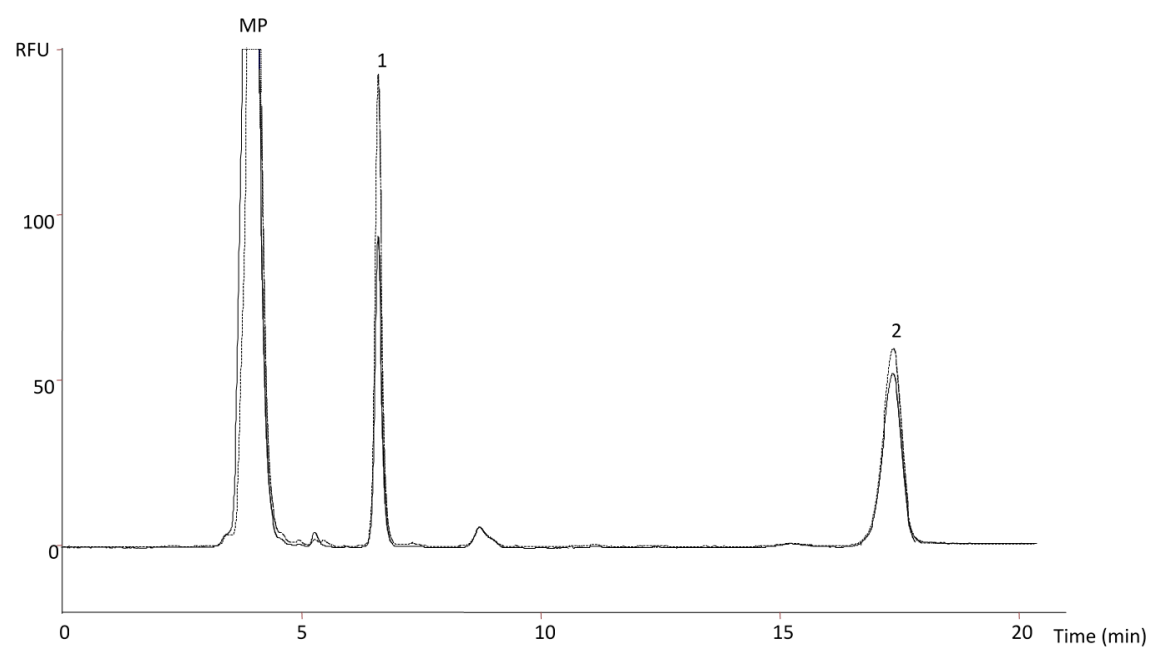

(A)

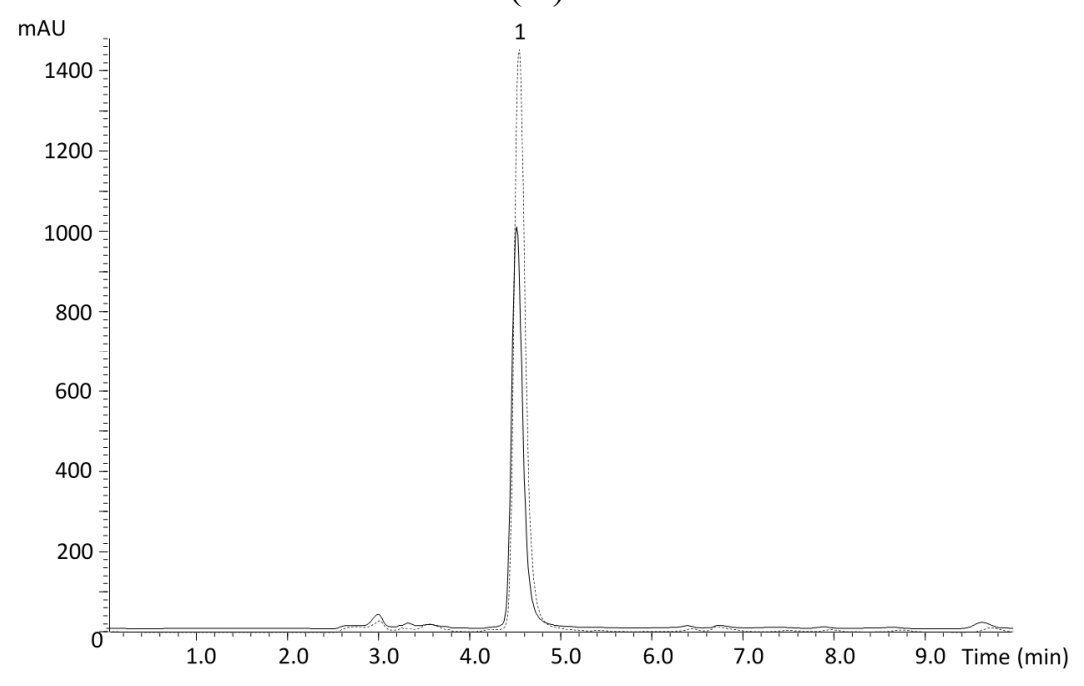

(B)

Figure 2. HPLC chromatograms of $\alpha$-tocopherol [(A), MP-mobile phase; 1 - $\alpha$-tocopherol; 2 - tocol] and ascorbic acid [(B), 1-ascorbic acid] in the dried pulp of Chislet variety for the year 2011 (----- January and _- April). 
Exemplifying chromatograms (Chislet variety) representing the results obtained for $\alpha$-tocopherol (Figure 2A) and ascorbic acid (Figure 2B) are shown to highlight the upper amounts obtained in January 2011.

These higher levels in antioxidant compounds were reflected by the measured antioxidant activity, as it can be deduced from the results obtained for DPPH scavenging activity (in 2011, Figure 3A), reducing power (in 2011, Figure 3B and 2012, Figure 3C) and TBARS formation inhibition (in 2012, Figure 3D).
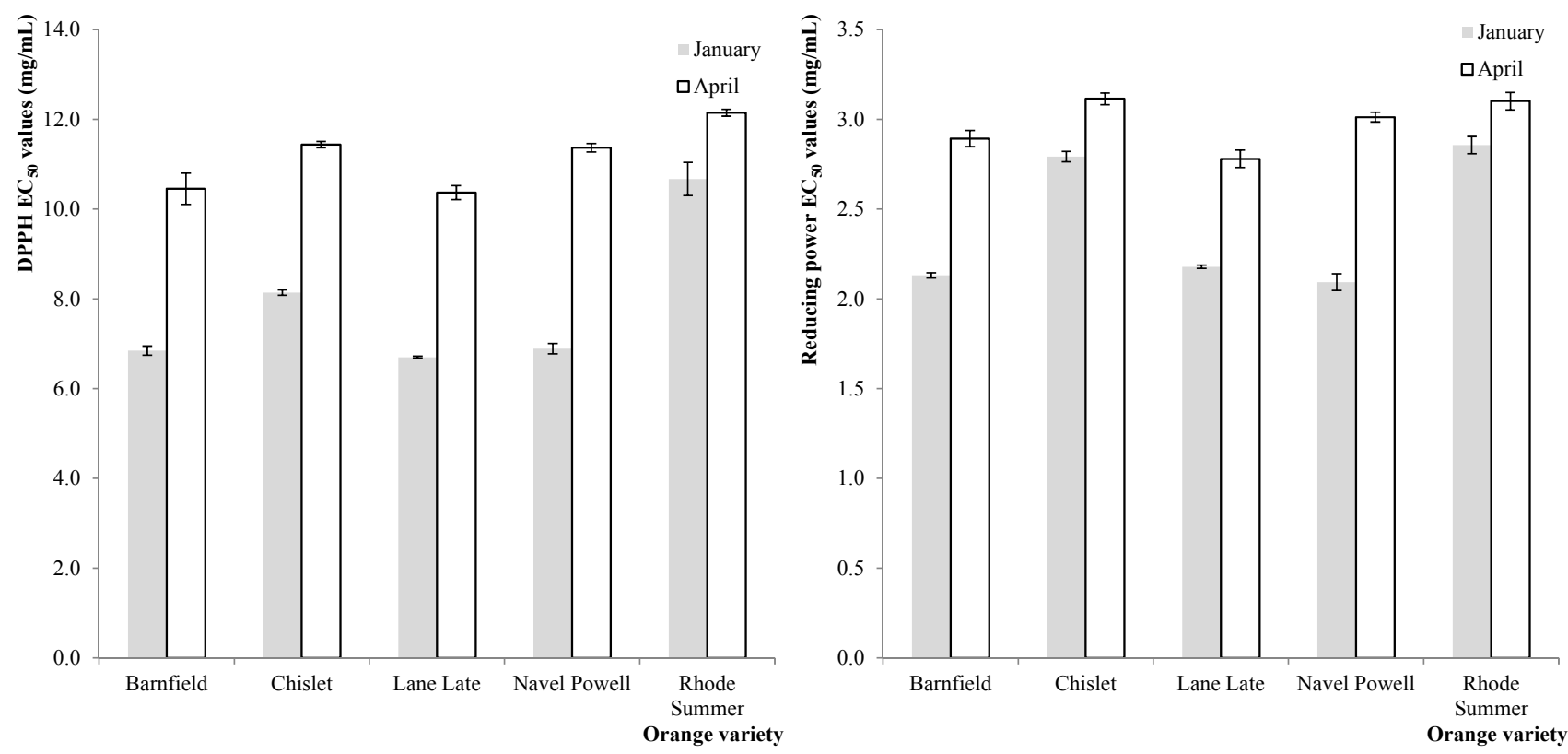

(A)
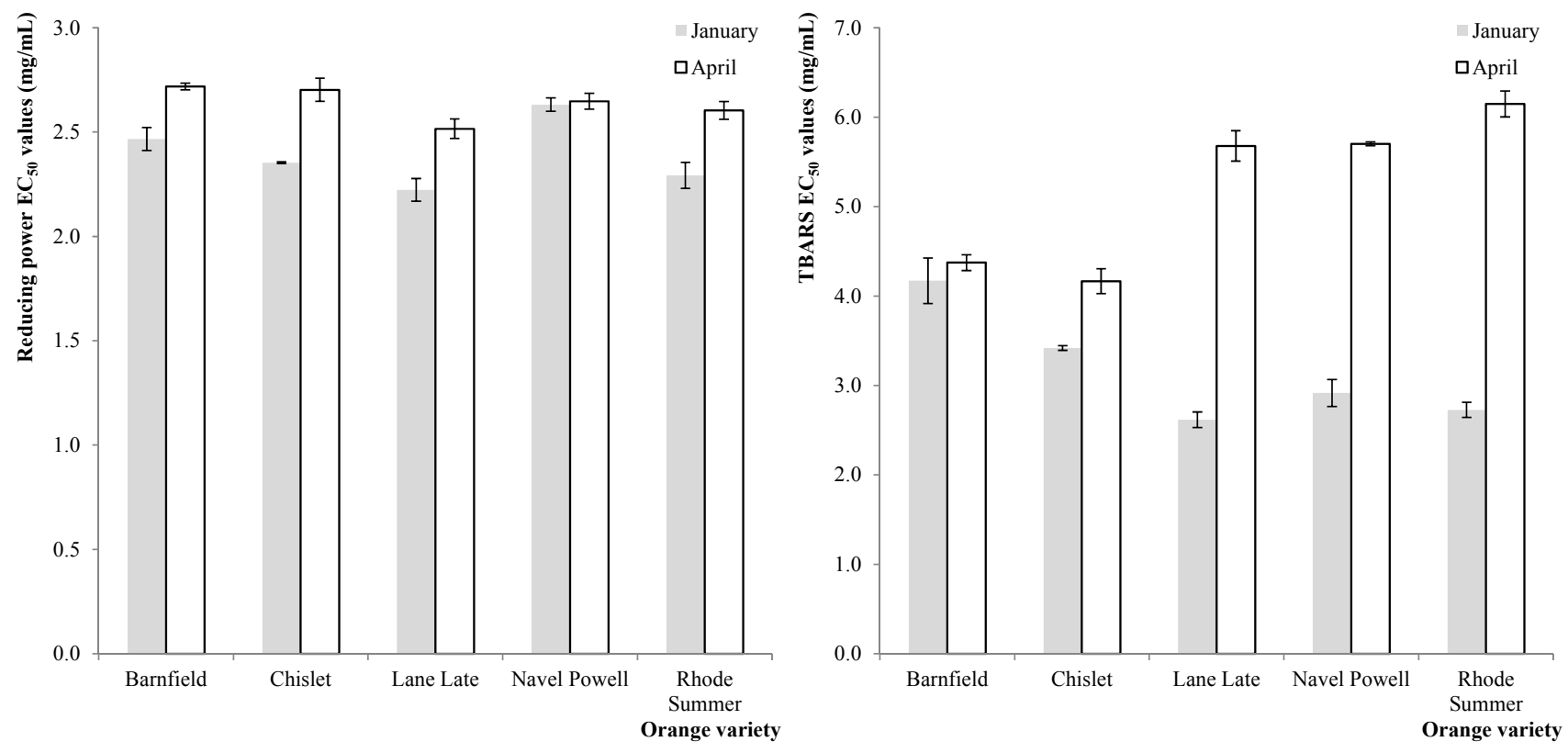

(C)

Figure 3. Estimated marginal mean plots representing the effect of HS on the antioxidant properties of $C$. sinensis fruits: (A) DPPH scavenging activity (2011); (B) reducing power (2011); (C) reducing power (2012); and (D) TBARS formation inhibition (2012). 
In what concerns the OV effect, some tendencies could also be identified; namely, the lower levels of ascorbic acid in Rhode Summer (in 2012, Figure 4A), and the weaker antioxidant activity verified for this variety for DPPH scavenging activity (in 2011, Figure 4B) and TBARS formation inhibition (in 2011, Figure 4C). Other identified tendency was the lower $\beta$-carotene bleaching inhibition shown by the Barnfield variety (in 2011, Figure 4D).
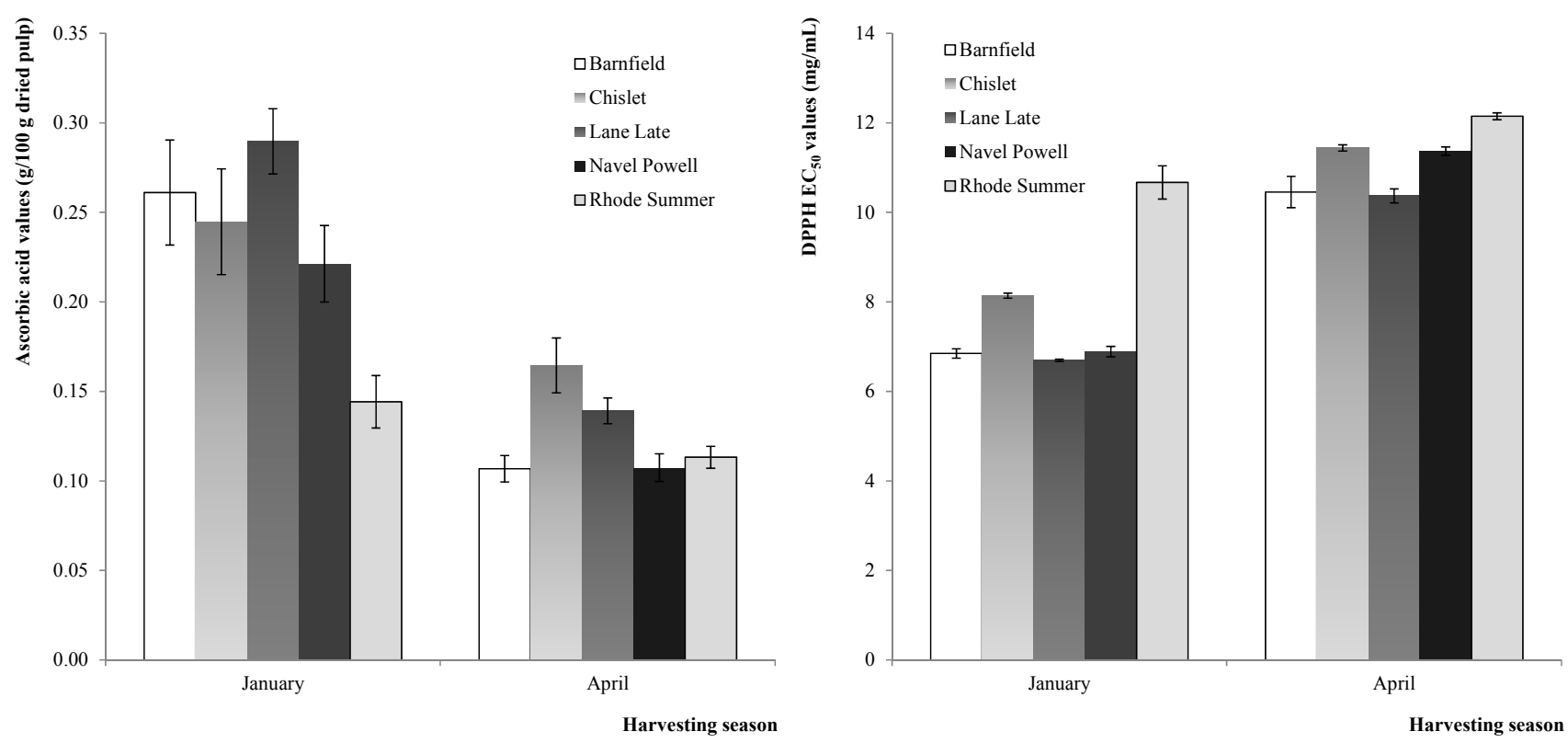

(A)
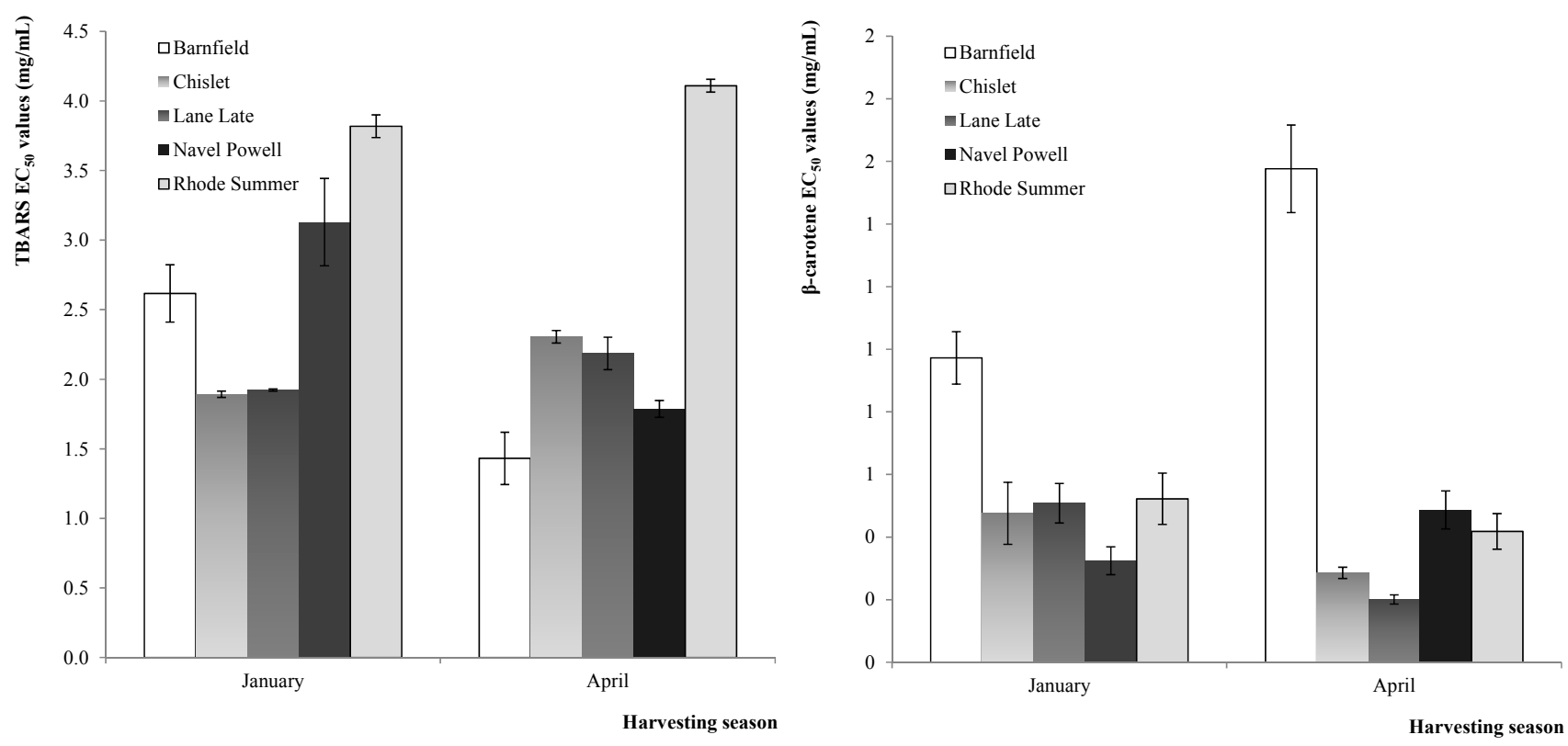

(C)

Figure 4. Estimated marginal mean plots representing the effect of OV on the antioxidant parameters of $C$. sinensis fruits: (A) ascorbic acid (2012); (B) DPPH scavenging activity (2011); (C) TBARS formation inhibition (2011); and (D) $\beta$-carotene bleaching inhibition (2011).

In general, the antioxidant activity, together with the levels of vitamins showed a higher variation in response to the effect of the HS when compared to the effect of OV. In fact, the harvesting season has 
been previously reported as inducing significant changes in sweet orange [15], as in other Citrus species [16] antioxidant properties.
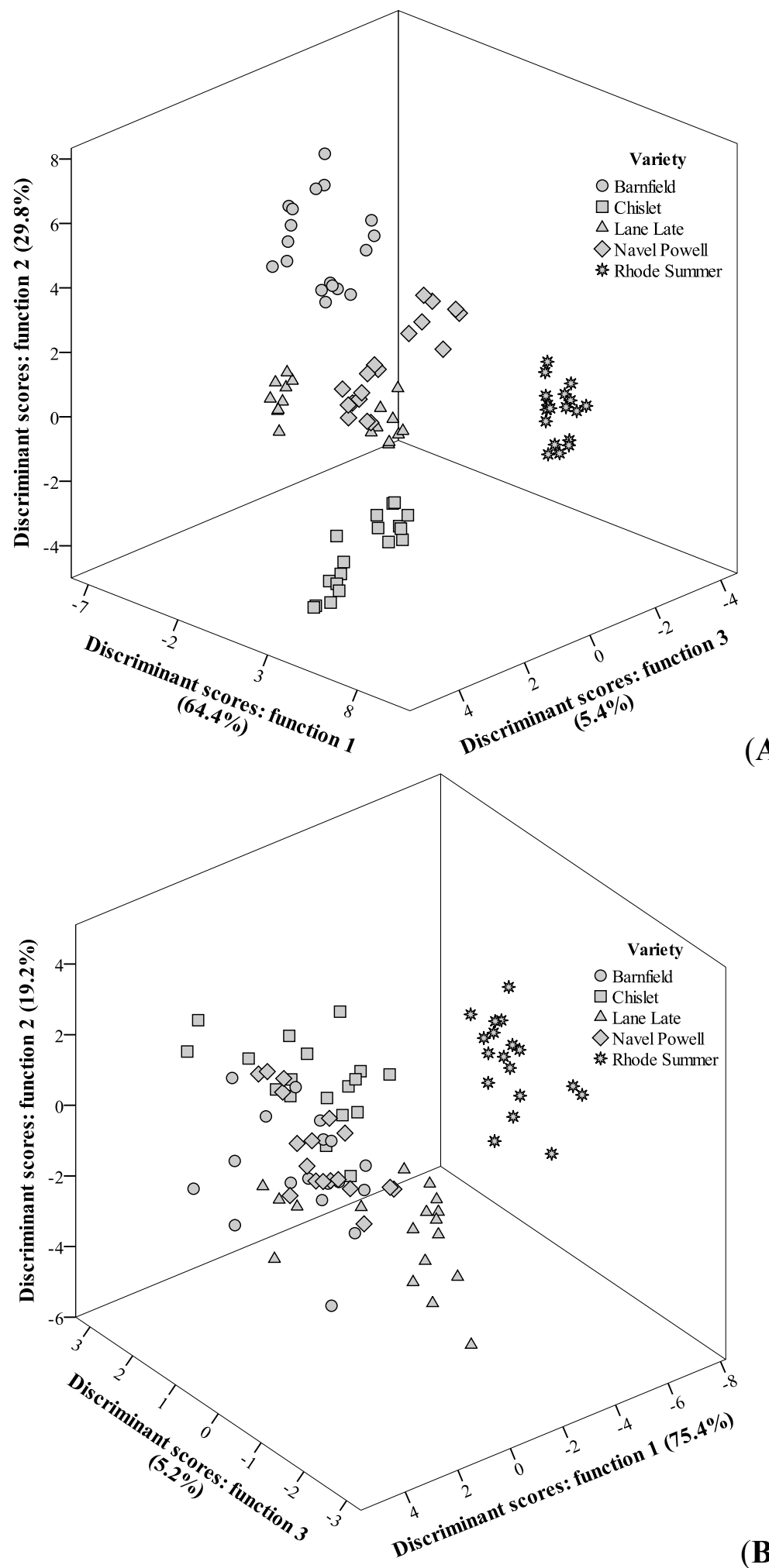

(A)

Figure 5. Discriminant scores scatter plot of the canonical functions defined for antioxidant parameters results according with OV for the years 2011 (A) and 2012 (B).

Aiming to understand the concerted effects of OV and HS on the antioxidant activity and vitamin amounts, two linear discriminant analyses (LDA) were applied, one for each single year. The 
significant independent variables (results for antioxidant activity assays and antioxidant compound levels) were selected using the stepwise method of the LDA, by evaluating the Wilks' $\lambda$ test results. Only those variables with a statistically significant classification performance $(p<0.05)$ were kept in the analysis.

In the case of OV effect, and starting with the analysis for year 2011, four significant functions were defined, from which the first three were plotted (Figure 5), including $99.6 \%$ of the results variance (function 1: 64.4\%; function 2: $29.8 \%$; function 3: 5.4\%).

As it can be immediately depicted from the discriminant scores distribution, the tested groups (Barnfield, Chislet, Lane Late, Navel Powell and Rhode Summer) were almost completely separated. Function 1 was mostly correlated with DPPH scavenging activity and TBARS formation inhibition, contributing to the separation of Rhode Summer variety, which presented higher $\mathrm{EC}_{50}$ values for those two assays (Table 1). Function 2, more strongly correlated with $\beta$-carotene bleaching inhibition, had a higher effect on the separation of Barnfield variety, which had higher $\mathrm{EC}_{50}$ values in that assay. Function 3 was more correlated with $\beta$-carotene bleaching inhibition and TBARS formation inhibition but it did not contribute in great extent to separate any of the varieties. In terms of classification performance, the corresponding contingency matrix (Table 2) gave values of sensitivity and overall specificity of $89 \%$ within the leave-one-out cross-validation procedure, which may be considered as acceptable values. It is interesting to verify that only Lane Late and Navel Powell showed misclassified cases (6 Lane Late were classified as Navel Powell and 4 Navel Powell were classified as Lane Late).

Table 2. Contingency matrix obtained using linear discriminant analysys based on antioxidant activity and antioxidant contents of sweet orange varieties (OV).

\begin{tabular}{|c|c|c|c|c|c|c|c|}
\hline \multirow{2}{*}{$\mathbf{O V}$} & \multicolumn{5}{|c|}{ Predicted Group Membership } & \multirow{2}{*}{ Total } & \multirow{2}{*}{ Sensitivity (\%) } \\
\hline & Barnfield & Chislet & Lane Late & Navel Powell & Rhode Summer & & \\
\hline \multicolumn{8}{|c|}{2011} \\
\hline Barnfield & 18 & 0 & 0 & 0 & 0 & 18 & 100 \\
\hline Chislet & 0 & 18 & 0 & 0 & 0 & 18 & 100 \\
\hline Lane Late & 0 & 0 & 12 & 6 & 0 & 18 & 67 \\
\hline Navel Powell & 0 & 0 & 4 & 14 & 0 & 18 & 78 \\
\hline Rhode Summer & 0 & 0 & 0 & 0 & 18 & 18 & 100 \\
\hline total & 18 & 18 & 16 & 20 & 18 & 90 & 89 \\
\hline Specificity $(\%)$ & 100 & 100 & 75 & 70 & 100 & 89 & \\
\hline \multicolumn{8}{|c|}{2012} \\
\hline Barnfield & 11 & 1 & 0 & 6 & 0 & 18 & 61 \\
\hline Chislet & 1 & 15 & 2 & 0 & 0 & 18 & 83 \\
\hline Lane Late & 2 & 0 & 16 & 0 & 0 & 18 & 89 \\
\hline Navel Powell & 6 & 0 & 0 & 12 & 0 & 18 & 67 \\
\hline Rhode Summer & 0 & 0 & 0 & 0 & 18 & 18 & 100 \\
\hline total & 20 & 16 & 18 & 18 & 18 & 90 & 80 \\
\hline Specificity (\%) & 55 & 94 & 89 & 67 & 100 & 81 & \\
\hline
\end{tabular}


Concerning the results for samples harvested during 2012, the discriminant model also selected four significant functions, which included $100.0 \%$ of the observed variance. The graph representation (Figure 5) of the three first functions (function 1: 75.4\%, function 2: 19.2\%, function 3: 5.2\%) did not show the assayed groups as separated as in the case of year 2011, but some differences among OV are still evident. Function 1 was mostly correlated with ascorbic acid content, contributing to the separation of Rhode Summer variety (which presented lower levels of this vitamin). Function 2 was also more highly correlated with ascorbic acid, favoring the separation of Lane Late variety (which presented the maximum levels of this vitamin). Function 3 correlated better with $\beta$-carotene bleaching inhibition, contributing to separate Chislet variety (which presented low $\mathrm{EC}_{50}$ values for this antioxidant activity assay). The classification ability was not as high as that obtained for the year 2011 (Table 2$)$, but the values for sensitivity $(80 \%)$ and overall specificity $(81 \%)$ within the leave-one-out cross-validation procedure, may still be considered as acceptable values. Despite some misclassified samples, it is relevant to verify that, as it happened for the results from the year 2011, all Rhode Summer samples were correctly classified, which might indicate that this variety has, in fact, differences in its antioxidant activity when compared to the other assayed varieties.

Regarding the combined effect of HS, samples harvested in each one of the months were clearly separated and classified with 100\% accuracy, with the same result being obtained for both years. A single function was defined in each case (the number of defined functions equals the number of levels for a determined factor less one), more correlated with $\alpha$-tocopherol content in year 2011, and $\alpha$-tocopherol content and TBARS formation inhibition in year 2012.

\section{Experimental Section}

\subsection{Samples}

Five sweet orange varieties (Barnfield, Chislett, Lane Late, Navel Powell and Rhode Summer), all belonging to Navel group (midseason varieties) were grown in western Andalusia (Huelva, Spain) on a plot of $9000 \mathrm{~m}^{2}\left(37^{\circ} 39^{\prime} 56^{\prime \prime} \mathrm{N}, 6^{\circ} 35^{\prime} 10.06^{\prime \prime} \mathrm{W}\right.$; UTM coordinates: X: 712,306.23 Y: 417,095.95).

The oranges were harvested in two harvesting seasons, at the beginning and end of the season (January and April). Seven-year-old trees grafted on Carrizo citrange were selected. The experimental design was a randomized block with four replications and an experimental unit of three trees per variety. The references to the test plot climatological data were collected from the nearest station weather. The weather showed for this period was Mediterranean weather type with a regime of low seasonal rainfall and a marked summer drought. The annual rainfall was $688 \mathrm{~mm}$ and evapotranspiration $\left(\mathrm{ET}_{0}\right) 1400 \mathrm{~mm}$.

The production yield of each tree presented similar values $(\approx 73 \mathrm{~kg} /$ tree $)$ for all varieties. Samples harvesting was performed in two consecutive years (2011 and 2012). After being collected and subsequently transported from the field to the lab (keeping cold), the samples were stored at $8{ }^{\circ} \mathrm{C}$ until further use. For each variety and harvesting season, 10 oranges were pooled and the mixed pulp was divided in three similar amounts. Fruit's pulp was lyophilized (FreeZone 4.5 model 7750031, Labconco, Kansas City, MO, USA), reduced to a fine dried powder (20 mesh), mixed to obtain homogenous samples, and stored in a desiccator, protected from light, until further analysis. 
All samples reached the minimum requirements for quality standards imposed by regulation (color index $>6$; maturity index $>6.5$; equatorial diameter $>53 \mathrm{~mm}$ and over $33 \%$ juice) (EC Regulation No. 1221/2008).

\subsection{Standards and Reagents}

Ethyl acetate $99.8 \%$ and n-Hexane 95\% were of HPLC grade from Fisher Scientific (Lisbon, Portugal). Trolox (6-hydroxy-2,5,7,8-tetramethylchroman-2-carboxylic acid), $\alpha$-tocopherol and ascorbic acid standards were purchased from Sigma (St. Louis, MO, USA). Racemic tocol, $50 \mathrm{mg} / \mathrm{mL}$, was purchased from Matreya (Pleasant Gap, PA, USA). 2,2-Diphenyl-1-picrylhydrazyl (DPPH) was obtained from Alfa Aesar (Ward Hill, MA, USA). Methanol and all other chemicals were of analytical grade and purchased from common sources. Water was treated in a Milli-Q water purification system (TGI Pure Water Systems, Greenville, SC, USA).

\subsection{Antioxidant Activity Evaluation}

Each lyophilized sample $(0.5 \mathrm{~g})$ was extracted by stirring with $20 \mathrm{~mL}$ of methanol/water $(80: 20, v / v)$ for $1 \mathrm{~h}$ and subsequently filtered through Whatman No. 4 paper. The residue was then extracted with $20 \mathrm{~mL}$ of methanol/water $(80: 20, v / v)$ for $1 \mathrm{~h}$. The combined hydro-alcoholic extracts were evaporated at $40{ }^{\circ} \mathrm{C}$ (rotary evaporator Büchi R-210, Flawil, Switzerland) to dryness and re-dissolved in methanol/water $(80: 20, v / v)$ for antioxidant activity assays $(40 \mathrm{mg} / \mathrm{mL})$. Successive dilutions were made from the stock solution and submitted to the in vitro assays already described by Martins et al. [17], to evaluate the antioxidant activity of the samples. The sample concentrations $(\mathrm{mg} / \mathrm{mL})$ providing $50 \%$ of antioxidant activity or 0.5 of absorbance (EC50) were calculated from the graphs of antioxidant activity percentages (DPPH, $\beta$-carotene/linoleate and TBARS assays) or absorbance at $690 \mathrm{~nm}$ (ferricyanide/Prussian blue assay) against sample concentrations. Trolox was used as a positive control and the assays were performed at room temperature with dimmed light.

\subsubsection{Reducing Power by Ferricyanide/Prussian Blue Assay}

The extract solutions with different concentrations $(0.5 \mathrm{~mL})$ were mixed with sodium phosphate buffer $(200 \mathrm{mmol} / \mathrm{L}, \mathrm{pH} 6.6,0.5 \mathrm{~mL})$ and potassium ferricyanide $(1 \% \mathrm{w} / \mathrm{v}, 0.5 \mathrm{~mL})$. The mixture was incubated at $50{ }^{\circ} \mathrm{C}$ for $20 \mathrm{~min}$, and trichloroacetic acid $(10 \% \mathrm{w} / \mathrm{v}, 0.5 \mathrm{~mL})$ was added. The mixture $(0.8 \mathrm{~mL})$ was poured in the 48 wells plate, the same with deionized water $(0.8 \mathrm{~mL})$ and ferric chloride $(0.1 \% \mathrm{w} / \mathrm{v}, 0.16 \mathrm{~mL})$, and the absorbance was measured at $690 \mathrm{~nm}$ in ELX800 Microplate Reader (Bio-Tek Instruments, Inc.; Winooski, VT, USA).

\subsubsection{DPPH Radical-Scavenging Activity Assay}

This methodology was performed using the Microplate Reader mentioned above. The reaction mixture on 96-well plate consisted of a solution by the well of the extract solutions with different concentrations $(30 \mu \mathrm{L})$ and methanolic solution $(270 \mu \mathrm{L})$ containing DPPH radicals $\left(6 \times 10^{-5} \mathrm{~mol} / \mathrm{L}\right)$. The mixture was left to stand for $30 \mathrm{~min}$ in the dark, and the absorption was measured at $515 \mathrm{~nm}$. The radical scavenging activity (RSA) was calculated as a percentage of DPPH discoloration using the 
equation: $\% \mathrm{RSA}=[(\mathrm{ADPPH}-\mathrm{As}) / \mathrm{ADPPH}] \times 100$, where As is the absorbance of the solution containing the sample, and ADPPH is the absorbance of the DPPH solution.

\subsubsection{Inhibition of $\beta$-Carotene Bleaching or $\beta$-Carotene/Linoleate Assay}

A solution of $\beta$-carotene was prepared by dissolving $\beta$-carotene $(2 \mathrm{mg})$ in chloroform $(10 \mathrm{~mL})$. Two milliliters of this solution were pipetted into a round-bottom flask. The chloroform was removed at $40{ }^{\circ} \mathrm{C}$ under vacuum and linoleic acid (40 mg), Tween 80 emulsifier $(400 \mathrm{mg})$, and distilled water $(100 \mathrm{~mL})$ were added to the flask with vigorous shaking. Aliquots $(4.8 \mathrm{~mL})$ of this emulsion were transferred into test tubes containing extract solutions with different concentrations $(0.2 \mathrm{~mL})$. The tubes were shaken and incubated at $50{ }^{\circ} \mathrm{C}$ in a water bath. As soon as the emulsion was added to each tube, the zero time absorbance was measured at $470 \mathrm{~nm}$. $\beta$-Carotene bleaching inhibition was calculated using the following equation: (Absorbance after $2 \mathrm{~h}$ of assay/initial absorbance) $\times 100$.

\subsubsection{Thiobarbituric Acid Reactive Substances (TBARS) Assay}

Porcine (Sus scrofa) brains were obtained from officially slaughtered animals, dissected, and homogenized with a vortex in an ice-cold Tris-HCl buffer $(20 \mathrm{mM}, \mathrm{pH} 7.4)$ to produce a 1:2 w/v brain tissue homogenate, which was centrifuged at $3000 \mathrm{~g}$ for $10 \mathrm{~min}$. An aliquot $(100 \mu \mathrm{L})$ of the supernatant was incubated with the different concentrations of the sample solutions $(200 \mu \mathrm{L})$ in the presence of $\mathrm{FeSO}_{4}(10 \mathrm{mM} ; 100 \mu \mathrm{L})$ and ascorbic acid $(0.1 \mathrm{mM} ; 100 \mu \mathrm{L})$ at $37{ }^{\circ} \mathrm{C}$ for $1 \mathrm{~h}$. The reaction was stopped by the addition of trichloroacetic acid $(28 \% \mathrm{w} / \mathrm{v}, 500 \mu \mathrm{L})$, followed by thiobarbituric acid (TBA, 2\%, w/v, $380 \mu \mathrm{L}$ ), and the mixture was then heated at $80{ }^{\circ} \mathrm{C}$ for $20 \mathrm{~min}$. After centrifugation at $3000 \mathrm{~g}$ for $10 \mathrm{~min}$ to remove the precipitated protein, the color intensity of the malondialdehyde (MDA)-TBA complex in the supernatant was measured by its absorbance at $532 \mathrm{~nm}$. The inhibition ratio (\%) was calculated using the following formula: Inhibition ratio $(\%)=[(\mathrm{A}-\mathrm{B}) / \mathrm{A}]$ $\times 100 \%$, where A and B were the absorbance of the control and the sample solution, respectively.

\subsection{Vitamins Content}

\subsubsection{Tocopherols}

BHT solution in hexane $(10 \mathrm{mg} / \mathrm{mL} ; 100 \mu \mathrm{L}$ ) and IS solution in hexane (tocol; $50 \mu \mathrm{g} / \mathrm{mL} ; 400 \mu \mathrm{L}$ ) were added to the sample prior to the extraction procedure. In order to avoid tocopherols oxidation, the samples were protected from light and heat. The samples $(\sim 500 \mathrm{mg})$ were homogenized with methanol $(4 \mathrm{~mL})$ by vortex mixing $(1 \mathrm{~min})$. Subsequently, hexane $(4 \mathrm{~mL})$ was added and again vortex mixed for 1 min. After that, saturated $\mathrm{NaCl}$ aqueous solution $(2 \mathrm{~mL})$ was added, the mixture was homogenized ( $1 \mathrm{~min}$ ), centrifuged ( $5 \mathrm{~min}, 4000 \mathrm{~g}$ ) and the clear upper layer was carefully transferred to a vial. The sample was re-extracted twice with hexane. The combined extracts were taken to dryness under a nitrogen stream, redissolved in $2 \mathrm{~mL}$ of $n$-hexane, dehydrated with anhydrous sodium sulfate, filtered through $0.2 \mu \mathrm{m}$ nylon filters from Whatman, transferred into a dark injection vial prior to the analysis [18]. Analysis was performed in a HPLC system consisted of an integrated system with a pump (Knauer, Smartline system 1000, Berlin, Germany), degasser system (Smartline manager 5000), an auto-sampler (AS-2057 Jasco, Easton, MD, USA), and a fluorescence detector (FP-2020; Jasco) programmed for 
excitation at $290 \mathrm{~nm}$ and emission at $330 \mathrm{~nm}$. The compounds were identified by chromatographic comparisons with authentic standards. Quantification was based on the fluorescence signal response of each standard, using the IS (tocol) method and by using calibration curves obtained from commercial standards of each compound. The results were expressed in mg per $100 \mathrm{~g}$ of dry pulp.

\subsubsection{Ascorbic Acid}

Samples ( $\sim 0.5 \mathrm{~g})$ were extracted by stirring with $10 \mathrm{~mL}$ of meta-phosphoric acid $\left(25^{\circ} \mathrm{C}\right.$ at $\left.150 \mathrm{rpm}\right)$ protected from light for $45 \mathrm{~min}$ and subsequently filtered through Whatman No. 4 paper [19]. Ascorbic acid was analyzed by ultra-fast liquid chromatography (UFLC, Shimadzu 20A series, Shimadzu Corporation, Kyoto, Japan) coupled with a photodiode array detector (PDA) as previously optimized and described by the authors [19]. The quantification was made by comparison of the area of the peaks recorded at $245 \mathrm{~nm}$ with the calibration curve obtained from commercial standard of L-ascorbic acid. The results were expressed in $g$ per $100 \mathrm{~g}$ of dry pulp.

\subsection{Statistical Analysis}

For each sample, all the extractions were performed in triplicate; each replicate was also measured three times. Data were expressed as mean \pm standard deviation. All statistical tests were performed at a 5\% significance level using IBM SPSS Statistics for Windows, version 22.0. (IBM Corp., Armonk, NY, USA).

An analysis of variance (ANOVA) with type III sums of squares was performed using the GLM (General Linear Model) procedure of the SPSS software. The dependent variables were analyzed using 2-way ANOVA, with the factors "orange variety" (OV) and "harvesting season" (HS). When a statistically significant interaction $(\mathrm{OV} \times \mathrm{HS})$ was detected, the two factors were evaluated simultaneously by the estimated marginal means plots for all levels of each single factor. Alternatively, if no statistical significant interaction was verified, means were compared using Tukey's honestly significant difference (HSD) multiple comparison test.

Stepwise Linear Discriminant Analysis (LDA) was used to verify if differences found for antioxidant activity and bioactive compound contents were high enough to discriminate the evaluated OV (Barnfield, Chislet, Lane Late, Navel Powell and Rhode Summer) as also to conclude which of the HS (January or April) optimizes the indicated properties. A stepwise technique, using the Wilks's $\lambda$ method with the usual probabilities of $F$ (3.84 to enter and 2.71 to remove) was applied to select variables. This procedure followed a combination of forward selection and backward elimination steps; i.e., before a new variable is selected to be included, it is verified whether all previously selected variables remain significant. The combination of variables is defined in a way that the first function furnishes the most general discrimination between groups, the second provides the second most, and so on. To verify which canonical discriminant functions were significant, the Wilks' $\lambda$ test was applied. To keep a more realistic data modulation, a leave-one-out cross-validation procedure was carried out to assess the model performance. 


\section{Conclusions}

Overall, the results obtained in this work proved that the differences in antioxidant activity and related compounds naturally existing in sweet orange varieties are overcome by the effects of the harvesting season. In fact, some particular compounds, especially $\alpha$-tocopherol, as well as specific antioxidant activity indicators, such as the TBARS formation inhibition, are strongly altered by the harvesting season of sweet orange. When comparing the results of consecutive years, changes observed in 2012 showed less marked differences among the studied sweet orange varieties. Nevertheless, Rhode Summer variety was the less active variety in both years (as confirmed in the LDA), allowing saying that this would not be the preferable choice as a target to enhance the overall characteristics of oranges. Concerning the harvesting season, January resulted in a better option than April, when considering either antioxidant activity or vitamin contents.

\section{Acknowledgments}

The authors are grateful to Foundation for Science and Technology (FCT, Portugal) for financial support to the research center CIMO (strategic project PEst-OE/AGR/UI0690/2011), J.C.M. Barreira grant (SFRH/BPD/72802/2010) and L. Barros researcher contract under "Programa Compromisso com Ciência-2008". Vanessa Cardeñosa is grateful to IFAPA for the fellowship obtained for the development of her $\mathrm{PhD}$ thesis and for financial support from IFAPA internal funds (strategic project PP.TRA:TRA2010.14.; 80\% financed with FEDER funds).

\section{Author Contributions}

Conducted bibliographic research and data organization: Vanessa Cardeñosa, Lillian Barros and Isabel C.F.R. Ferreira; Conducted the antioxidant activity assays and vitamins evaluation: Vanessa Cardeñosa and Lillian Barros; Performed the statistical analysis: Vanessa Cardeñosa and João C.M. Barreira; Conducted the samples collection and preparation: Vanessa Cardeñosa, Francisco Arenas and José M. Moreno-Rojas; Wrote or contributed to the writing of the manuscript: Vanessa Cardeñosa, João C.M. Barreira and Isabel C.F.R. Ferreira; Revised the manuscript writing: Francisco Arenas, José M. Moreno-Rojas and Isabel C.F.R. Ferreira.

\section{Conflicts of Interest}

The authors declare no conflict of interest.

\section{References}

1. Halliwell, B. Free radicals and antioxidants - quo vadis? Trend Pharmacol. Sci. 2011, 32, 125-130.

2. Schreckinger, M.E.; Wang, J.; Yousef, G.; Lila, M.A.; de Mejia, E.G. Antioxidant capacity and in vitro inhibition of adipogenesis and inflammation by phenolic extracts of Vaccinium floribundum and Aristotelia chilensis. J. Agric. Food Chem. 2010, 58, 8966-8976. 
3. Mateos, R.; Lecumberri, E.; Ramos, S.; Goya, L.; Bravo, L. Determination of malondialdehyde (MDA) by high-performance liquid chromatography in serum and liver as a biomarker for oxidative stress-Application to a rat model for hypercholesterolemia and evaluation of the effect of diets rich in phenolic antioxidants from fruits. J. Chrom. B-Anal. Technol. Biomed. Life Sci. 2005, 827, 76-82.

4. Carocho, M.; Ferreira, I.C.F.R. A review on antioxidants, prooxidants and related controversy: Natural and synthetic compounds,. screening and analysis methodologies and future perspectives. Food Chem. Toxicol. 2013, 51, 15-25.

5. Dhuique-Mayer, C.; Caris-Veyrat, C.; Ollitrault, P.; Curk, F.; Amiot, M.J. Varietal and interspecific influence on micronutrient contents in citrus from the Mediterranean area. J. Agric. Food Chem. 2005, 53, 2140-2145.

6. Del Caro, A.; Piga, A.; Vacca, V.; Agabbio, M. Changes of flavonoids, vitamin C and antioxidant capacity in minimally processed citrus segments and juices during storage. Food Chem. 2004, 84, 99-105.

7. Rauf, A.; Uddin, G.; Ali, J. Phytochemical analysis and radical scavenging profile of juices of Citrus sinensis, Citrus anrantifolia, and Citrus limonum. Org. Med. Chem. Lett. 2014, 4, 5.

8. Roussos, P.A.; Paziodimou, C.; Kafkaletou, M. Assessment of twenty-two Citrus cultivars (oranges, mandarins and lemons) for quality characteristics and phytochemical's concentration. In Ii Balkan Symposium on Fruit Growing; Coman, M., Chitu, E., Eds.; Int Soc Horticultural Science: Leuven, Belgium, 2013; Volume 981, pp. 657-663.

9. Ferreira, I.C.F.R.; Barros, L.; Abreu, R.M.V. Antioxidants in wild mushrooms. Curr. Med. Chem. 2009, 16, 1543-1560.

10. Halliwell, B. Antioxidants in human health and disease. Ann. Rev. Nutri. 1996, 16, 33-50.

11. Schwenke, D.C. Does lack of tocopherols and tocotrienols put women at increased risk of breast cancer? J. Nutr. Biochem. 2002, 13, 2-20.

12. Brigelius-Flohe, R.; Traber, M.G. Vitamin E: function and metabolism. FASEB J. 1999, 13, 1145-1155.

13. Ghasemi, K.; Ghasemi, Y.; Ebrahimzadeh, M.A. Antioxidant activity, phenol and flavonoid contents of 13 citrus species peels and tissues. Pak. J. Pharm. Sci. 2009, 22, 277-281.

14. Milella, L.; Caruso, M.; Galgano, F.; Favati, F.; Padula, M.C.; Martelli, G. Role of the cultivar in choosing clementine fruits with a high level of health-promoting compounds. J. Agric. Food Chem. 2011, 59, 5293-5298.

15. Huang, R.; Xia, R.; Hu, L.; Lu, Y.; Wang, M. Antioxidant activity and oxygen-scavenging system in orange pulp during fruit ripening and maturation. Sci. Hortic. 2007, 113, 166-172.

16. Moulehi, I.; Bourgou, S.; Ourghemmi, I.; Tounsi, M.S. Variety and ripening impact on phenolic composition and antioxidant activity of mandarin (Citrus reticulate Blanco) and bitter orange (Citrus aurantium L.) seeds extracts. Ind. Crop. Prod. 2012, 39, 74-80.

17. Martins, A.; Barros, L.; Carvalho, A.M.; Santos-Buelga, C.; Fernandes, I.P.; Barreiro, F.; Ferreira, I.C.F.R. Phenolic extracts of Rubus ulmifolius Schott flowers: Characterization, microencapsulation and incorporation into yogurts as nutraceutical sources. Food Funct. 2014, 5, 1091-1100. 
18. Barros, L.; Heleno, S.A.; Carvalho, A.M.; Ferreira, I.C.F.R. Lamiaceae often used in Portuguese folk medicine as a source of powerful antioxidants: Vitamins and phenolics. LWT Food Sci. Technol. 2010, 43, 544-550.

19. Pereira, C.; Barros, L.; Carvalho, A.M.; Ferreira, I.C.F.R. Use of UFLC-PDA for the Analysis of Organic Acids in Thirty-Five Species of Food and Medicinal Plants. Food Anal. Methods 2013, 6, $1337-1344$.

Sample Availability: Samples of the five sweet orange varieties (Barnfield, Chislett, Lane Late, Navel Powell and Rhode Summer) are available from the authors.

(C) 2015 by the authors; licensee MDPI, Basel, Switzerland. This article is an open access article distributed under the terms and conditions of the Creative Commons Attribution license (http://creativecommons.org/licenses/by/4.0/). 